\title{
DIFFERENCES IN MOTOR ABILITIES OF TRACK AND FIELD ATHLETES AND CALISTHENICS PRACTITIONERS ${ }^{1}$
}

\author{
UDC: $796.42 .012 .1(497.11)$ \\ 796.015 .52 \\ https://doi.org/10.18485/snip.2021.11.1.en.2
}

Dragan Klisarić

Faculty of Sport and Physical Education, University of Belgrade, Serbia ${ }^{3}$

Milan Matić

Faculty of Sport and Physical Education, University of Belgrade, Serbia

\begin{abstract}
The subject of this research are the motor abilities of track and field athletes and calisthenics practitioners. The aim of the study was to examine the differences in the motor abilities of track and field athletes and calisthenics practitioners. The research was conducted on a sample of a total of 11 participants from the City of Belgrade: 6 track and field athletes (group 1) and 5 calisthenics practitioners (group 2). The standing long jump (SLJ), standing triple jump (STJ), $20 \mathrm{~m}$ sprinting, 50m sprinting (20 flying start) tests were used for the assessment of motor abilities. Descriptive and comparative statistical methods were used for data processing. The results of the research showed that track and field athletes perform better in the examined motor abilities. The results of descriptive statistics showed that track and field athletes perform better in all tests that assess the ability of power, speed, and acceleration. The results of comparative statistics, using the t-test for independent samples showed that a statistically significant difference $(\mathrm{p}<0.05)$ was found between the groups. These differences can be attributed to the training of track and field athletes, which is more planned, systematic and specific in relation to calisthenics workouts.
\end{abstract}

Key words: tests, power, speed, acceleration

\section{INTRODUCTION}

Motor abilities are one of the key areas of scientific research in sports, recreation, and physical education. In addition, they are important for many occupations, such as police, army, fire department, etc., but also people's daily lives. Motor abilities are the possibilities of a person as a bio-psycho-social and cultural being, to achieve success in a certain activity (Kukolj, 2006). Motor abilities are innate, evolving, and can be improved.

The structure of motor abilities is the same in all people. By applying factor analysis in the study of the structure of motor abilities, the existence of a larger number of factors was noted, which implies the existence of a larger number of motor abilities and that the structure is multidimensional, i.e. that there is not just one motor ability (Fleishman, 1964). Of particular importance for scientific research is that motor abilities can be presented as a value, which, as such, can be expressed quantitatively and qualitatively.

Motor abilities include muscle force (strength), power, speed, endurance, agility, and flexibility (Kukolj, 2006). Force, power, and speed are mechanical properties of muscles that largely determine a person's motor

\footnotetext{
Paper received: 5 October 2020, edited: 14 November 2020, accepted for publication: 17 November 2020

$2 \square$ dklisaric94@gmail.com

3 Dragan Klisarić holds a MA degree in physical education and sport, obtained at the Faculty of Sport and Physical Education, at the University of Belgrade.
} 
abilities, on which successful performance of physical activities depends (Nedeljković, 2016). Power can also be seen as a function of body weight, height, or distance and time necessary to perform a certain activity (Fukuda, 2019). This definition refers to the practicality of testing and assessing power through tests, such as standing long jump and standing triple jump. Speed in physics is calculated over the quotient of the distance traveled and the time required to cross that distance $(\mathrm{V}=\mathrm{S} / \mathrm{t})$. Sprinting speed is a very conservative ability and is difficult to change (Čoh et al., 2007). Acceleration can be seen as a rate of increase in speed.

The assessment and analysis of motor abilities play a key role in sports, recreation, and other types of physical activity. Assessment and analysis are not an end in themselves, but they seek to gather useful information, which could help identify weaknesses or strengths of athletes, improve the training process, repair or prevent injuries, gain information about a certain population, etc. In order for the information to be useful, it is necessary that the conditions in which the test is realized be as similar as possible to the conditions in which the athlete competes (Suzović, 2019).

Differences in the level of motor abilities exist between athletes in different sports, sports disciplines, and specific positions that players have in their team. The differences can be subtle, i.e. more or less pronounced. Apart from the differences, there are also similarities between athletes. Athletes can differ from each other in terms of muscle strength ( $\mathrm{N}$; newton), power (W; watt), speed $(\mathrm{m} / \mathrm{s})$, etc. In order to obtain relevant data in science and practice, different tests, instruments, and technology are used, depending on the working conditions and possibilities of application.

Some differences in motor abilities are obvious and for some, it is necessary to conduct certain tests, in order to perceive the realistic state of motor abilities. For example, there are obvious differences in motor abilities between judokas and cyclists, running and throwing track and field events. The difference is quite more sensitive in similar sports, such as the $100 \mathrm{~m}, 200 \mathrm{~m}$, and $400 \mathrm{~m}$ sprinting disciplines in track and field. For example, sprinters competing in the $100 \mathrm{~m}$ event achieved a result of $285.73 \mathrm{~cm}$ in the standing long jump test, while sprinters in the $200 \mathrm{~m}$ event achieved $256.00 \mathrm{~cm}$ and sprinters in the $400 \mathrm{~m}$ achieved $277.20 \mathrm{~cm}$ in the same test (Maćkała, Fostiak \& Kowalski, 2015; Maćkala et al., 2015; Phogat \& Ahlawat, 2015). This indicates that sprinters who compete in the 100 $\mathrm{m}$ running event have a higher degree of development of power in the lower extremities in relation to the sprinters in the $200 \mathrm{~m}$ and $400 \mathrm{~m}$ events, respectively. Such differences arise as a result of the improvement of certain motor abilities to a greater or lesser extent.

Track and field is based on natural forms of movement such as walking, running, jumping, and throwing. Also, calisthenics practitioners perform exercises that are based on natural forms of movement and using their own body weight as a load. Unlike track and field athletes, calisthenics practitioners are not focused on achieving athletic, top results. This paper looks into the differences in the motor abilities of track and field athletes and calisthenics practitioners. The subject of this paper is the motor abilities of track and field athletes and calisthenics practitioners. The aim of the study was to examine the differences in the motor abilities of track and field athletes and calisthenics practitioners.

\section{METHOD}

The following methods were used in the research: theoretical method, descriptive method and comparative method.

\section{Sample of participants}

The research was conducted on a sample of 11 male participants from the City of Belgrade. The first group consisted of 6 sprinters from the "Red Star" track and field club, junior age $18 \pm 0.5$. The second group consisted of 5 calisthenics practitioners, aged $21 \pm 2.1$, who are not registered in the sports system and who do not compete. The calisthenics practitioners perform exercises, where the load is based on the practitioner's body weight, including equipment and props that do not significantly change the practitioner's body weight.

\section{Sample of variables}

The sample of variables are motor tests designed to assess motor abilities:

- standing long jump (cm) to assess leg power,

- standing triple jump (cm) to assess leg power,

- $20 \mathrm{~m}$ sprinting (s) to assess acceleration and

- $50 \mathrm{~m}$ (20 m flying start) sprinting (s) to assess maximum running speed. 


\section{Data processing methods}

Microsoft Office Excel was used for data processing, within which the following values were calculated through descriptive analysis:

- arithmetic mean,

- standard deviation,

- minimum value,

- maximum value and

- coefficient of variation.

Also, through comparative statistics, using t-tests for independent samples, statistically significant differences between groups were established, at the level of statistical significance $(\mathrm{p}<0.05)$.

\section{RESULTS}

The results of the research are presented in two subchapters. The first one presents the results of descriptive statistics, and the second one presents the results of comparative statistics of the motor abilities of track and field athletes and calisthenics practitioners.

\section{Results of descriptive statistics}

The results of descriptive statistics are presented individually for track and field athletes (group 1) and calisthenics practitioners (group 2). Table 1 shows the results of descriptive indicators of the motor abilities of track and field athletes (group 1).

Table 1. Results of descriptive statistics of motor abilities of track and field athletes (group 1)

\begin{tabular}{lccccc}
\hline Variables & M & SD & MIN & MAX & cV\% \\
\hline SLJ $(\mathrm{cm})$ & 266.00 & 22.03 & 236.00 & 298.00 & 8.28 \\
\hline STJ $(\mathrm{cm})$ & 775.00 & 32.75 & 746.00 & 830.00 & 4.22 \\
\hline 20 m sprinting $(\mathrm{s})$ & 2.60 & 0.20 & 2.51 & 3.05 & 7.74 \\
\hline Sprint $50 \mathrm{~m}(\mathrm{~s})$ & 2.91 & 0.27 & 2.70 & 3.43 & 9.15 \\
\hline
\end{tabular}

From Table 1 it can be argued that the average distance value in the standing long jump test is $266.00 \mathrm{~cm}$, while the absolute measure of deviation is $22.03 \mathrm{~cm}$. The minimum value is $236.00 \mathrm{~cm}$ and the maximum is 298.00 $\mathrm{cm}$. The average value of the distance in the standing triple jump test is $775.00 \mathrm{~cm}$, while the absolute measure of deviation is $32.75 \mathrm{~cm}$. The minimum value is $746.00 \mathrm{~cm}$ and the maximum $830.00 \mathrm{~cm}$. The average time value in the $20 \mathrm{~m}$ sprinting test is $2.60 \mathrm{~s}$, and the absolute measure of deviation is $0.20 \mathrm{~s}$. The minimum value is $2.51 \mathrm{~s}$, and the maximum is $3.05 \mathrm{~s}$. The average time value in the $50 \mathrm{~m}$ sprinting test is $2.91 \mathrm{~s}$, and the absolute measure of deviation is $0.27 \mathrm{~s}$. The minimum value is $2.70 \mathrm{~s}$ and the maximum is $3.43 \mathrm{~s}$. The coefficient of variation for all tests ranges from $4.22 \%$ to $9.15 \%$, which is less than $30 \%$, which means that the group is homogeneous from the aspect of the observed motor ability variables.

Table 2 shows the results of descriptive indicators of the motor abilities of calisthenics practitioners (group 2).

Table 2. Results of descriptive statistics of motor abilities of calisthenics practitioners (group 2)

\begin{tabular}{lccccc}
\hline Variables & M & SD & MIN & MAX & cV\% \\
\hline SLJ $(\mathrm{cm})$ & 236.00 & 15.57 & 220.00 & 260.00 & 6.60 \\
\hline STJ $(\mathrm{cm})$ & 620.00 & 56.90 & 530.00 & 670.00 & 9.18 \\
\hline 20 m sprinting (s) & 3.55 & 0.26 & 3.26 & 3.86 & 7.29 \\
\hline 50 m sprinting (s) & 3.69 & 0.29 & 3.33 & 4.11 & 7.73 \\
\hline
\end{tabular}

From Table 2, it can be perceived that the average value of the distance in the standing long jump test is $236.00 \mathrm{~cm}$, while the absolute measure of deviation is $15.57 \mathrm{~cm}$. The minimum value is $220.00 \mathrm{~cm}$ and the maximum 
one is $260.00 \mathrm{~cm}$. The average value of the distance in the standing triple jump test is $620.00 \mathrm{~cm}$, while the absolute measure of deviation is $56.90 \mathrm{~cm}$. The minimum value is $530.00 \mathrm{~cm}$ while the maximum is $670.00 \mathrm{~cm}$. The average time value in the $20 \mathrm{~m}$ sprinting test is $3.55 \mathrm{~s}$, and the absolute measure of deviation is $0.26 \mathrm{~s}$. The minimum value is 3.26 and the maximum one is $3.86 \mathrm{~s}$. The average time value in the $50 \mathrm{~m}$ sprinting test is $3.69 \mathrm{~s}$, and the absolute measure of deviation is $0.29 \mathrm{~s}$. The minimum value is 3.33 and the maximum is $4.11 \mathrm{~s}$. The coefficient of variation for all tests ranges from $6.60 \%$ to $9.18 \%$, which is less than $30 \%$, which indicates that the group is homogeneous in terms of the observed motor ability variables.

\section{Results of comparative statistics}

Table 3 show the results of the difference in the motor abilities of track and field athletes (group 1) and calisthenics practitioners (group 2) using the t-test for independent samples, at the level of statistical significance $(\mathrm{p}<0.05)$.

Table 3. Results of comparative statistics of motor abilities of track and field athletes and calisthenics practitioners

\begin{tabular}{|c|c|c|c|c|c|}
\hline Test & & SLJ (cm) & $\mathrm{STJ}(\mathrm{cm})$ & $20 \mathrm{~m} \mathrm{~S}(\mathrm{~s})$ & $50 \mathrm{~m} \mathrm{~S}(\mathrm{~s})$ \\
\hline \multirow{5}{*}{$\begin{array}{l}\text { Track and field } \\
\text { athletes } \\
\text { (group 1) }\end{array}$} & M & 266.00 & 775.00 & 2.60 & 2.91 \\
\hline & SD & 22.03 & 32.75 & 0.20 & 0.27 \\
\hline & MIN & 236.00 & 746.00 & 2.51 & 2.70 \\
\hline & MAX & 298.00 & 830.00 & 3.05 & 3.43 \\
\hline & $\mathrm{cV} \%$ & 8.28 & 4.22 & 7.74 & 9.15 \\
\hline Test & & SLJ $(\mathrm{cm})$ & $\mathrm{STJ}(\mathrm{cm})$ & $20 \mathrm{~m} \mathrm{~S}(\mathrm{~s})$ & $50 \mathrm{~m} \mathrm{~S}(\mathrm{~s})$ \\
\hline \multirow{6}{*}{$\begin{array}{l}\text { Calisthenics } \\
\text { practitioners } \\
\text { (group 2) }\end{array}$} & M & 236.00 & 620.00 & 3.55 & 3.69 \\
\hline & $\mathrm{SD}$ & 15.57 & 56.90 & 0.26 & 0.29 \\
\hline & MIN & 220.00 & 530.00 & 3.26 & 3.33 \\
\hline & MAX & 260.00 & 670.00 & 3.86 & 4.11 \\
\hline & $\mathrm{cV} \%$ & 6.60 & 9.18 & 7.29 & 7.73 \\
\hline & t-test & 0.03 & 0.01 & 0.01 & 0.01 \\
\hline
\end{tabular}

From Table 3, which shows the results of comparative statistics, obtained by applying the t-test for independent samples, it can be concluded that in all variables of motor skills there are statistically significant differences $(\mathrm{p}<0.05)$ in the sample of track and field athletes and calisthenics practitioners.

\section{DISCUSSION}

By analyzing the descriptive data of motor abilities, it can be concluded that track and field athletes achieved better average values on all tests, which indicates that they perform better in all observed motor abilities than calisthenics practitioners. More precisely, from the aspect of power, the track and field athletes achieved an average value of $266.00 \mathrm{~cm}$ in the standing long jump (SLJ) test, while the calisthenics athletes achieved a value of 236.00 $\mathrm{cm}$ in the standing long jump test, which is a difference of $30 \mathrm{~cm}$. Then, in the standing triple jump test (STJ), the track and field athletes achieved an average value of $775.00 \mathrm{~cm}$, while the calisthenics practitioners achieved a value of $620.00 \mathrm{~cm}$, which makes a difference of $155 \mathrm{~cm}$. In addition, in terms of the ability to accelerate, the track and field athletes achieved an average value of $2.60 \mathrm{~s}$ in the $20 \mathrm{~m}$ sprinting test, while the calisthenics practitioners achieved a value of $3.55 \mathrm{~s}$, which is a difference of $0.95 \mathrm{~s}$. In addition, from the aspect of maximum speed, the track and field athletes achieved a value of $2.91 \mathrm{~s}$ in the $50 \mathrm{~m}$ sprinting test, and the calisthenics practitioners achieved a value of $3.69 \mathrm{~s}$, which makes a difference of $0.78 \mathrm{~s}$. In addition to the results of descriptive analysis, the results of comparative analysis, using a t-test, found statistically significant differences $(p<0.05)$ between groups. It is 
important to note that the track and field athletes performed the tests in sprinting shoes and on a track, while the calisthenics practitioners performed the tests in sports sneakers and on a grass sports field.

The results of this research are in agreement with the research of Maćkała et al. (Maćkała, Fostiak \& Kowalski, 2015) in which track and field athletes achieve better results in tests that assess power, speed, and acceleration compared to the students of the Faculty of Sports. The norms for elite adult track and field athletes for the standing long jump test were provided by Chu (1996), which were summarized by Fukuda (2019) and presented using a threepoint scale. According to the three-point scale (Low - 30th percentile; Typical - 50th percentile and High - 70th percentile), the track and field athletes in this study are on the 50th percentile, while the calisthenics practitioners are on the 30th percentile scale. In addition, Chu provides the norms for elite adult track and field athletes for the standing triple jump test, according to which the track and field athletes are in the range of $61-70 \%$, while the calisthenics practitioners are in the range of $41-50 \%$. In comparison with the given norms, it is necessary to take into account the current condition (age, training experience, field of expertise, etc.) of the track and field athletes and calisthenics practitioners. As Chu specifies, the given norms should serve as an inspiration for future elite athletes. Since the sample of the variables of motor abilities is included only for the lower part of the body, the question arises as to what differences exist in the motor abilities of the upper part of the body.

Limitations in this research refer to the conditions for performing motor tests. It could be assumed that if the conditions for performing the tests were equal for both groups, the results of the research would show smaller differences in motor abilities. In order to draw more complete conclusions, it is necessary to increase the sample of participants.

\section{CONCLUSION}

The obtained research results show that track and field athletes perform better in the examined motor abilities of power, speed and acceleration in relation to calisthenics practitioners. This suggests that the planned, systematic and specific training of the "Red Star" track and field athletes, along with the work and guidance of coaches and resources of the "Red Star" track and field club contributes to improving the motor skills of power, speed and acceleration to a greater extent compared to the motor skills of calisthenics practitioners. In relation to the norms of elite adult athletes, the track and field athletes in this research are recommended to work on improving the power and abilities on which it depends (muscle force, i.e. strength, and speed). Also, calisthenics practitioners who want to improve leg power are recommended to work out based on exercises that involve a plyometric regime of muscle work, since it can be executed using their own body weight. In order to draw relevant and more complete conclusions about the motor abilities and differences in the motor abilities of track and field athletes and calisthenics practitioners, a larger sample of participants and variables is proposed in future research.

\section{REFERENCES}

1. Chu, D.A. (1996). Explosive Power and Strength: Complex Training for Maximum Results. Champaign, IL: Human Kinetics.

2. Čoh, M., Tomazin, K. \& Rausavljevic, N. (2007). Differences in morphological and biodynamic characteristics in maximum speed and acceleration between two groups of female sprinters. Biology of Sport, 24(2), 115.

3. Fleishman, E.A. (1964). The structure and Measurement of Physical Fitness. Englewood Cliffs: Prentice-Hall.

4. Fukuda, D. H. (2019). Assessments for Sport and Athletic Performance. Champaign, IL: Human Kinetics.

5. Kukolj, M. (2006). Antropomotorika. Beograd: Fakultet sporta i fizičkog vaspitanja Univerzitet u Beogradu.

6. Phogat, W. S. \& Ahlawat, R. P. (2015). Relationship of Selected Bio-motor Variables to the Performance of 400 Meter Male Sprinters. International Journal of Physical Education, Sports and Health, 1(5), 46-48.

7. Maćkała, K., Fostiak, M. \& Kowalski, K. (2015). Selected determinants of acceleration in the 100m sprint. Journal of human kinetics, 45(1), 135-148.

8. Maćkala, K., Michalski, R., Čoh, M. \& Rausavljević, N. (2015). The relationship between $200 \mathrm{~m}$ performance and selected anthropometric variables and motor abilities in male sprinters. Collegium antropologicum, 39 (Supplement 1), 69-76. 
9. Nedeljković, A. (2016). Relacija sila-brzina u složenim pokretima: nova metoda u testiranju mišićne sile, snage i brzine. Beograd: Univerzitet u Beogradu, Fakultet sporta i fizičkog vaspitanja.

10. Suzović, D. (2019). Izdržljivost u sportu procena u laboratorijskim i terenskim uslovima. Beograd: Fakultet sporta i fizičkog vaspitanja, Univerzitet u Beogradu. 